\title{
RECEPCIÓN DEL ARBITRAJE COMERCIAL INTERNACIONAL EN CHILE DESDE UNA ÓPTICA JURISPRUDENCIAL. UNA REVISIÓN INELUDIBLE*
}

\author{
RECEPTION OF THE INTERNATIONAL COMMERCIAL \\ ARBITRATION IN CHILE FROM A JURISPRUDENTIAL OPTICS. \\ AN UNAVOIDABLE REVIEW
}

\section{María Fernanda VÁsQUez PaLma**}

\begin{abstract}
RESUMEN: El presente artículo analiza las sentencias judiciales que se han pronunciado en Chile sobre el arbitraje comercial internacional desde la dictación de la ley que rige la materia (2004), con el objeto de revisar cuál ha sido su acogida en relación a la institución arbitral y los principios que la rigen.

Palabras clave: acogida, arbitraje comercial internacional, justicia estatal, Chile.

ABSTRACT: The present article analyses the judicial decisions that have been declared in Chile on international commercial arbitration, since the enactment of the law governing the subject (2004), in order to review which has been its reception in relation to the arbitral institution and the principles that govern it.
\end{abstract}

Key words: reception, international commercial arbitration, state justice, Chile.

\section{CONTEXTUALIZACIÓN PREVIA}

Hace menos de una década en Chile no existía una regulación concreta para el arbitraje comercial internacional, tal realidad comenzó a replantearse hace algunos años, al comprenderse que la modernización del instituto constituía un camino sin retorno que debía enfrentarse.

\footnotetext{
* Este trabajo se inserta en el Proyecto Fondecyt ( $\mathrm{N}^{\circ}$ 11090227) en que la autora es investigadora responsable.

** Abogada. Licenciada en Derecho por la Universidad de Talca. Magíster y Doctora en Derecho por la Universidad Complutense de Madrid (s.c.l. por unanimidad). Profesora de Derecho Privado de la Facultad de Ciencias Jurídicas y Sociales de la Universidad de Talca. E mail: mfvasquez@utalca.cl.
}

Tabla de abreviaturas: CNUDMI/UNCITRAL: Comisión de las Naciones Unidas para el Derecho Mercantil Internacional; CNY: Convención de Nueva York, sobre reconocimiento de sentencias extranjeras; CG: Convención de Ginebra, sobre arbitraje comercial internacional; LA: Ley de arbitraje; LACI: Ley de arbitraje comercial internacional, Chile (2004); LMU: Ley Modelo Uncitral; RCEA: Revista Española de la Corte de Arbitraje. 
La existencia de un claro vacío normativo en la materia ${ }^{1}$, y una creciente necesidad de cubrir nacida de la apertura económica que Chile había sostenido en los últimos años, forzaron la creación de un proyecto de ley con dos objetivos claros: modernizar el arbitraje internacional y convertir a Chile en una sede arbitral relevante en la región. El criterio que siguió el legislador, en tal sentido, fue abrigar el modelo de Ley arbitral recomendado por la Comisión de las Naciones Unidas para el Derecho Mercantil Internacional (CNUDMI/UNCITRAL) ${ }^{2}$, y adoptado por la mayoría de los países que pretendían estar a la vanguardia en esta materia ${ }^{3}$. Se dio vida, entonces, a la Ley sobre arbitraje comercial internacional, No 19.971 (LACI) ${ }^{4}$, el año 2004.

A poco más de seis años desde que la LACI entró en vigencia en nuestro país ${ }^{5}$, corresponde preguntarse por el panorama existente en la materia desde una perspectiva práctica, y no hay mejor forma que hacerlo que analizar las sentencias y líneas jurisprudenciales que se han sostenido hasta ahora. Tal inquietud no solo surge por el hecho de tratarse de una legislación relativamente nueva, sino más aún, porque esta regulación vino a conmover todo el sistema imperante hasta la fecha en el Derecho arbitral chileno interno -que aún se mantiene-, por lo que las dudas que se plantearon en su momento sobre la acogida que tendría la ley no fueron menores.

Para ello, he indagado y recogido - por vez primera- las sentencias emanadas de los máximos tribunales chilenos de justicia a partir del año 2005, que se han pronunciado sobre arbitraje comercial internacional, desde diversas perspectivas. En este recorrido comprobaremos que se han asentado la mayoría de los pilares rectores de la institución arbitral concebida desde una óptica moderna, por lo que podemos asegurar que la cultura arbitral internacional ha impregnado con claridad tales decisiones judiciales. Ello permite transmitir ciertas dosis de seguridad sobre uno de los principales factores que inciden en la elección de una sede arbitral internacional, en tanto puede afirmarse que Chile se encuentra en un buen pie a estos efectos.

Con una finalidad didáctica, dividí el presente artículo de acuerdo a principios y/o criterios rectores que guían el instituto arbitral, con el objeto de tener claridad sobre la

\footnotetext{
${ }^{1}$ Si bien, como se indica en el mensaje del Proyecto de Ley (Boletín No 3252-10), Chile había ratificado instrumentos internacionales en la materia, como la Convención sobre el Reconocimiento y la Ejecución de las Sentencias Arbitrales Extranjeras de 10 de Junio de 1958 y la Convención Interamericana sobre Arbitraje Comercial Internacional de 30 de Enero de 1975, la regulación contenida en tales acuerdos era muy limitada, pues se dirigían principalmente a normar el reconocimiento de sentencias arbitrales dictadas en el extranjero.

2 Véase texto: http://www.uncitral.org

${ }^{3}$ Realizando una defensa a la actualidad y modernidad de la Ley Modelo y su influencia, véase CREMADES (1999). Por la misma línea, SANDOVAL (2007) pp. 485-517.

${ }^{4}$ Uno de los criterios que guió al grupo de trabajo desde el inicio de sus actividades fue el no apartarse de la Ley Modelo, pues no se deseaba dar la imagen de que se estaba haciendo un experimento a nivel internacional; por el contrario, se perseguía mostrar seriedad y confianza ante la comunidad jurídica y empresarial internacional, y brindar seguridad a los inversionistas y contrapartes extranjeras, creando un régimen jurídico aplicable a la resolución de controversias internacionales. De esta manera, se consideró que el tener una ley eventualmente idéntica al modelo facilitaría enormemente el conocimiento de la normativa chilena por los actores extranjeros, los que podrían reaccionar con incertidumbre ante cualquier desvío de la Ley Modelo. FigueroA (2007) pp. 391-404.

${ }^{5}$ Publicada en el Diario Oficial el 29 de septiembre de 2004.
} 
importancia del fallo en comento. Expondré, en primer lugar, las líneas matrices de estos principios, para luego plasmar un pequeño resumen de los fallos que se han pronunciado sobre los mismos. Finalizaré con unas breves conclusiones.

\section{REVISIÓN DE LAS LÍNEAS JURISPRUDENCIALES}

\subsection{CONSAGRACIÓN DEL PRINCIPIO DE INTERVENCIÓN MÍNIMA}

Este principio tiene por objeto dar certeza a las partes sobre la posible interferencia judicial estatal, de modo que no se produzcan intervenciones inesperadas e inapropiadas ${ }^{6}$. Importa excluir todo poder general o residual dado a los tribunales en un sistema judicial nacional que no esté mencionado en la Ley arbitral, en tanto, tal como lo indica la historia de la LM, el recurso de la intervención de los tribunales durante las actuaciones arbitrales a menudo solo se utilizaba como una táctica dilatoria y constituía, con mayor frecuencia, un abuso de las actuaciones arbitrales más que una protección contra el abuso ${ }^{7}$. De este modo, el principio pretende respetar la autonomía del instituto arbitral, reconociendo - de paso- que esta no es autónoma totalmente, sino que requiere de la colaboración de los tribunales estatales para el éxito y eficacia del arbitraje, pero las mismas no pueden extenderse más allá de ciertas actuaciones precisas que poseen una finalidad perfectamente definida y coherente con la arquitectura de la institución.

El proyecto de ley, siguiendo los lineamientos de la Ley Modelo UNCITRAL (LMU), planteó el principio en comento en su Art. 5º estableciendo la intervención mínima de los tribunales estatales, mientras que en la siguiente disposición se fijó un radio restringido de posibilidades de acción de estos últimos en relación a un proceso arbitral. De la mano de ello, se concibe una única acción en contra de los laudos arbitrales (Art. 34), señalando de manera expresa y taxativa las causales que harán factible su ejercicio a diferencia del arbitraje doméstico en que se permite un multiplicidad de recursos y oportunidades de revisión de las sentencias arbitrales.

Su incorporación definitiva, sin embargo, fue objeto de un detenido análisis por el grupo de trabajo legislativo. Se sostuvo, por una parte, que la incorporación de aquel constituía un requisito sine qua non que se justificaba en la amplitud de la autonomía de las partes, que son capaces de entender las consecuencias del recurso arbitral, a diferencia de lo que sucede en el ámbito doméstico, donde el Estado asume un rol más proteccionista ${ }^{8}$; no obstante ello, se observó como duda por la propia $\mathrm{CS}^{9}$ y la Cámara de Diputados, que la consagración de este principio podría importar dejar atrás la aplicación de ciertos recursos que se estimaban, en términos generales, como irrenunciables por obedecer a un estatus supra partes, como sucede con los recurso de queja y

\footnotetext{
6 Sobre el tema, entre otros, véase: SENES (2007) p. 24; FERNÁNDEZ (2005) p. 626; VERDERA Y TUELLS (1994) pp. 137-177. En la misma dirección, BERNARDO SAN JOSÉ (2002), p. 2 y sgtes.; GOSWAMI (2001) pp. 111 y sgtes.

7 Anuario de la Comisión de las Naciones Unidas para el Derecho Mercantil, vol. XVI (1985) pp. 11 y sgtes.

8 SATELER (2007) pp. 386 y sgtes.

${ }^{9}$ Oficio de la CS, de 9 de julio de 2003, disponible en http://sil.congreso.cl/pags/index.html
} 
protección. La opinión mayoritaria se asentó en este sentido, entendiendo que los citados recursos tenían un claro sustrato constitucional, de manera que nada en el proyecto podía afectar su aplicabilidad. El Ejecutivo, sin contrariar tal idea, sostuvo que no era necesaria mención alguna sobre la posible aplicación de aquellos aludiendo a innumerables normas que, si bien hacían posible la renuncia de recursos, siempre dejaban a salvo la interposición de los mismos, porque en esencia son irrenunciables ${ }^{10}$.

De los referidos recursos el que más angustias suscitó, por sus dimensiones y consecuencias, fue el recurso de queja ${ }^{11}$. Parte de la doctrina ${ }^{12}$, intentando aminorar la discusión, señaló que no obstante la existencia de este recurso, en la práctica este sería imposible de deducir básicamente porque para su interposición se requeriría que la resolución no sea objeto de recurso alguno, lo que claramente no se cumplirá en la especie al existir el recurso de nulidad establecido en el Art. 34 de la citada ley ${ }^{13}$. En su oportunidad analizamos los postulados de este recurso y planteamos, al respecto, más de alguna duda razonable sobre dicho asunto ${ }^{14}$.

Pues bien, hasta el momento se han dictado algunos fallos que han debido pronunciarse sobre esta materia. De la lectura de los mismos, se extrae que los tribunales superiores han respetado el principio en comento en su sentido amplio, rechazando en lo concreto otros recursos deducidos en un arbitraje comercial internacional. Los revisaremos a continuación.

\section{A. Caso: "D'Arcy Masius Benton \& Bowles Inc. Chile Ltda. Otero Lathrop} Miguel". Corte de Apelaciones. No 865-2006. 25 de mayo de 2006

En juicio arbitral seguido en Santiago de Chile, se presenta un recurso de hecho que incide en una resolución dictada por un árbitro de derecho, designado por el Centro de Arbitraje y Mediación de la Cámara de Comercio de Santiago, en virtud de un

\footnotetext{
10 Bajo este mismo razonamiento lo resolvió el TC, que al pronunciarse sobre la constitucionalidad del mencionado precepto avaló esta interpretación al expresar que: "Según consta del Informe de la Comisión de Relaciones Exteriores del Senado, de fecha 11 de mayo de 2004, el profesor BERTELSEN señaló que la Corte Suprema de justicia, al informar el proyecto debía dejar a salvo la facultad que a aquélla otorga el Art. 79 de la Constitución Política de ejercer la Superintendencia directiva, correccional y económica de todos los tribunales de la nación, e igualmente el conocimiento del recurso de inaplicabilidad por inconstitucionalidad de las leyes que confiere el Art. 80 de la Carta Fundamental, opinión que él compartía (...). Que, teniendo presente lo anteriormente expuesto, y siguiendo el principio de buscar la interpretación de las normas que permitan resolver, dentro de lo posible, su conformidad con la Constitución, este Tribunal decidirá que los Arts. $5^{\circ}$ y 34, en cuanto señala en su primera parte "la petición de nulidad como único recurso del laudo arbitral" y en su número 1, son constitucionales en el entendido que dejan a salvo las atribuciones que la Constitución otorga a la Corte Suprema según quedó expuesto, así como también, las acciones jurisdiccionales que contempla la Carta Política a favor de quienes puedan verse afectados en sus derechos fundamentales por la aplicación de esta ley. Considerandos décimo sexto y décimo séptimo del citado fallo pronunciado con fecha 25 de agosto de 2004 ”.

11 Nos referiremos a este recurso en detalle.

12 Así, por ejemplo, Figueroa (2007) p. 406, señala que "confiamos en que la sapiencia de nuestros jueces no admitirá dicho recurso, ya que de lo contrario, se podría ver comprometido seriamente el principio de favor arbitri y de paso el poder constituir a Chile como sede de arbitrajes comerciales internacionales".

13 SATELER (2007) p. 388.

14 VÁSQUEZ (2009) pp. 41-57.
} 
convenio arbitral. Una de las partes del litigio, tanto al momento de suscribirse el contrato, como en el presente -su sucesora legal- tiene su establecimiento en París, Francia.

La parte demandada deduce un recurso de hecho sosteniendo que el contrato se había suscrito con anterioridad a la entrada en vigor de la Ley 19.971, sobre arbitraje comercial internacional, y que por ello, el procedimiento arbitral tenía que someterse a las normas que rigen el arbitraje chileno interno. La decisión de la Corte que rechaza el recurso de hecho deducido en la presente causa, se basa en el artículo $5^{\circ}$ de la Ley en referencia, que limita la participación de los tribunales ordinarios en el arbitraje internacional a los casos previstos en la Ley (Principio de intervención mínima).

En su fallo, la Primera Sala de la Corte sostuvo que la Ley No 19.971, de carácter procesal, rige desde el momento de su entrada en vigencia y las normas del Código de Procedimiento Civil y otras que regulaban estas materias al momento de celebrarse el contrato, no están comprendidas, en caso alguno, dentro de las que deben entenderse incorporadas al contrato a la fecha de su celebración.

La Corte agrega que lo alegado por la recurrente en orden a que esas normas legales, por ser su vigencia posterior a la fecha de celebración del contrato no serían aplicables en la especie, carece de fundamento, dado lo preceptuado en los Arts. 22 y 24 de la ley de 7 de octubre de 1861, sobre efecto retroactivo de las leyes.

De esta forma, se concluye que la Ley 19.971, la norma aplicable a la sazón, y de conformidad a lo establecido en el artículo $5^{\circ}$ antes transcrito, solo cabe resolver que la resolución en que incide el recurso de hecho no es susceptible de apelación, por lo cual deberá ser desestimado.

\section{B. Caso Rol No 2363-2010. Corte de Apelaciones de Santiago. 23 de julio de} 2010

Se interpuso recurso de queja contra el árbitro único que tuvo a su cargo el juicio arbitral desarrollado bajo las reglas del centro de arbitraje y mediación del CAM Santiago, de conformidad con la Ley 19.971.

La Corte de Apelaciones declaró inadmisible este recurso bajo le argumento que el Art. 34 de la Ley en cita solo contempla el recurso de nulidad como única vía de impugnación del laudo que se dicte en un arbitraje como el de la especie, excluyendo así aquel intentado en el presente juicio.

\section{Caso: "D’Arcy Masius Benton \& Bowles Inc. Chile Ltda. V. Carlos Eugenio} Jorquiera", Rol No 88-2006. 03 de mayo de 2006

Se dedujo recurso de protección en contra de una decisión pronunciada por el Presidente de la Cámara de Comercio de Santiago. Esta había confirmado la decisión del tribunal arbitral nombrado por el centro de arbitraje y mediación de la Cámara de Comercio (Santiago), en cuanto a que el procedimiento arbitral iba a ser sometido a la Ley $\mathrm{N}^{\circ} 19.971$ por cumplirse los requisitos de aplicación de esta. El recurrente invocó el inciso 4 del $\mathrm{N}^{\circ} 3$ del artículo 19 de la Constitución chilena, sosteniendo que el recurrido se habría atribuido una facultad jurisdiccional y, pretendiendo ser un Tribunal de 
Justicia, dictó una resolución mediante la cual instruía y ordenaba al tribunal arbitral cómo debía abordar la resolución de la contienda.

Al rechazar el recurso de protección, la Cuarta Sala de la Corte de Apelaciones falló que la ley en comento rige en Chile desde el día 4 de septiembre de 2004, y que a la fecha en que se solicitó a la Cámara de Comercio la designación de árbitro, dicha ley ya tenía vigencia. Por lo tanto, el árbitro, en su resolución de fecha 26 de diciembre de 2005, no hizo sino aplicar una ley que ya regía en Chile en materia de arbitraje comercial internacional. Asimismo, señala la sentencia que "las partes acordaron someter sus disputas, controversias o diferencias, a arbitraje de acuerdo con las reglas del Centro de Arbitraje de la Cámara de Comercio de Santiago, y esta aplica la Ley 19.971 en los casos de Arbitrajes Comerciales Internacionales, ya que es una garantía de certeza jurídica a las partes y demuestra, a la comunidad internacional, el funcionamiento adecuado e imparcial de la institucionalidad de nuestro país".

\subsection{AUTONOMÍA DEL INSTITUTO ARBITRAL}

Este principio, muy ligado al anterior, implica reconocer -entre otros efectos- ${ }^{15}$ que el tribunal arbitral es competente para conocer de un proceso arbitral y pronunciar las resoluciones pertinentes, lo que se condice con los efectos de todo convenio arbitral.

La autonomía de los tribunales arbitrales se refleja primordialmente en el grado de revisión que tienen los tribunales estatales sobre las resoluciones de los primeros. En el arbitraje doméstico existente en Chile, estos tienen posibilidad de pronunciarse sobre aspectos de fondo y forma de un arbitraje, lo que resta autonomía al generarse competencias compartidas; en el caso del arbitraje comercial internacional, tal escenario cambia diametralmente. Así, en lo relativo al control que podrán profesar los tribunales estatales en relación al laudo arbitral, la LACI establece la acción de nulidad (Art. 34) indicando, expresamente, cada una de las causales a partir de las cuales se hace procedente su interposición $^{16}$. La mayor parte de ellas dice relación con cuestiones objetivas que habrán de apreciarse de acuerdo a lo estipulado por las partes y lo dispuesto en la LACI, por lo que a los tribunales estatales se encontrarán inhibidos de efectuar un pronunciamiento que se extienda de dichas causales, o entrar a conocer el fondo del asunto.

Los temores que afloraron en la discusión de la LACI a este respecto fueron dos: los problemas que podrían suscitarse en lo relativo a la comprensión de algunas de las

\footnotetext{
15 Para un completo análisis de la injerencia de este principio en el instituto arbitral, véase, entre otros: Petsche (2005) pp. 3-4; Fernández Rozas (2005) pp. 605-636; M.I.M. Aboul-Enein (2001) p. 16; FERNÁNDEZ ROZAS (2005) p. 55; GONZÁlez CAMPOS (1975) p. 7; ARTUCH (1997) p. 53; CHILLÓN y MERINO (1991) p. 32; LORCA (2004) p. 1; VÁSQUEZ (2009) pp. 131-145; ChATTERJeEK (2003) pp. 539-560.

16 La mayor parte de la doctrina está conteste en calificar esta acción como rescisoria, constitutiva de petitum único e invariable, es decir, una acción que pretende dejar sin eficacia o privar de efectos al laudo arbitral atacando su fuerza de cosa juzgada por medio de algunos de los motivos previamente tasados en la ley que, en caso de ser estimados, producen un efecto constitutivo, pues crea una situación jurídica distinta de la habida hasta ese momento. Se trata de un proceso declarativo especial de carácter plenario que ha de fundarse en un motivo legal. En tal sentido, FERNÁNDEZ (2004) pp. 412-413; BARONA (2007) p. 1361; Hinojosa (2006) pp. 513-514; GONZÁLEZ-MONTES (2008) pp. 26-27.
} 
causales, tales como la noción de arbitrabilidad y orden público de Chile, que no cuentan con una clara delimitación (Art. 34); y el respeto que dicha norma tendría en la práctica.

Hasta ahora se puede entrever, a partir de la sentencia que expongo a continuación, que los tribunales de justicia chilenos han aplicado íntegramente la base y lógica de este recurso, despejando las interrogantes antes esbozadas.

En efecto, el caso "Publicis v. Árbitro MJV", Rol No 9134-2007, Corte de Apelaciones de Santiago, 4 de agosto de 2009, da cuenta de esta materia. En la especie, el laudo pronunciado por un árbitro ad hoc en un arbitraje comercial internacional con sede en Santiago de Chile fue objeto de la solicitud de nulidad prevista en el artículo 34 de la Ley sobre Arbitraje Comercial Internacional (LACI). La Corte de Apelaciones de Santiago aplicó la LACI, a pesar que la parte que se oponía al recurso sostenía su inaplicabilidad por haber sido el contrato celebrado con antelación a su entrada en vigor.

La parte reclamante alegó que el laudo arbitral se fundó en información contenida en un documento emanado de un tercero que no había sido acompañado legalmente a los autos, cuyo contenido no había sido ratificado por ese tercero declarando como testigo en la causa y que no tuvo oportunidad de refutar, determinándose los perjuicios a través de meras especulaciones y no de las pruebas de la causa. De la misma forma, sostuvo que el laudo contravenía el orden público procesal al violentar su derecho a la defensa, y por ende al debido proceso.

La Corte de Apelaciones competente recordó, en primer lugar, que el recurso de nulidad "viene a constituir un recurso extraordinario, de derecho estricto, donde la actuación del Tribunal se limita a verificar la concurrencia de las causales invocadas en relación a los hechos que las fundamentan. La acción otorga competencia a la Corte para examinar el cumplimiento de las formas del juicio arbitral, especialmente en cuanto a las garantías formales que la propia ley establece de modo imperativo, para asegurar una correcta génesis del laudo" (Considerando quinto).

Con respecto al fondo del recurso, la Corte sostuvo que los documentos obtenidos de la base de datos que sirvieron para determinar los perjuicios, no eran ajenos al proceso, ni por ende desconocidos para la recurrente, toda vez que la demandante los acompañó formalmente a fojas 578, los refirió en su presentación de fojas 1.308 , así como en la audiencia de reconocimiento. Al estar en conocimiento de los mismos, no resulta tampoco efectivo que no tuviera oportunidad para refutarlos, sobre todo si se tiene en cuenta que hizo uso de la citación conferida cuando fueron acompañados, y se encontraba presente en la diligencia de reconocimiento sin observar nada al respecto. Por lo demás, una vez puesto -el peritaje- en su conocimiento, pudo hacer -y así lo hizo- las observaciones que estimó pertinentes. En definitiva la demandada siempre tuvo conocimiento que se utilizaría como base para determinar los perjuicios, la información proveniente de una base de datos pública, cuyo detalle se agregó al proceso, por lo que no es posible sostener que el sentenciador haya apoyado su fallo en elementos probatorios inexistentes en el proceso o pruebas que no fueron introducidas al debate" (Considerando decimotercero). 
Por último, la Corte recalcó que el medio de prueba cuestionado por la recurrente no era "la prueba documental sino que la pericial, que tiene por finalidad auxiliar al Tribunal, en cuestiones de hecho, concretas, para las cuales se requiere de conocimientos especiales sobre alguna ciencia o arte, cuya naturaleza jurídica es distinta de la anterior y cuya eficacia se valora conforme a las reglas de la sana crítica, esto es, conforme a las reglas de la lógica, a las máximas de experiencia y a los aportes que surgen del desarrollo científico" (Considerando decimocuarto). Por las razones expuestas, la Corte concluyó que no se habían configurado las causales invocadas por la recurrente y rechazó el recurso de nulidad.

\subsection{PRINCIPIO COMPETENCIA-COMPETENCIA}

Este principio implica que debe ser el propio árbitro quien debe resolver los conflictos derivados del convenio arbitral, incluida la posible alegación de nulidad del contrato del cual puede formar parte el pacto arbitral y aún de este último, lo que se resume en la idea que el árbitro tiene competencia para revisar su propia competencia ${ }^{17}$. Esta potestad se entiende, desde una perspectiva positiva, como la manifestación o prolongación del convenio arbitral y sus efectos; y desde la óptica negativa, que los tribunales estatales quedan inhibidos de pronunciarse sobre esta materia por estar entregada a la justicia arbitral ${ }^{18}$.

El principio en comento presenta una clara raigambre contractual en cuanto son las partes quienes le confieren una competencia total al árbitro para resolver un determinado asunto, de lo cual se deriva que estos deben conocer incluso de su propia competencia para dar inicio al juicio arbitral y solo si comprueban que este es nulo o inválido, quedarán inhibidos de poder hacerlo. No se trata de una mera facultad del árbitro, ni de una concesión de las partes a su competencia, se entiende que se trata de una obligación por parte del árbitro una vez que ha aceptado el cargo, aún a falta de mención expresa, pues tiene el deber de revisar los cimientos del juicio que va a conducir, de lo contrario, podrá constituirse en responsable ante las partes. Con todo, si bien el principio arranca

\footnotetext{
${ }^{17}$ El principio "Kompetenz-Kompetenz" tuvo su origen en un fallo emitido por un Tribunal Superior en la República Federal de Alemania en el año 1955. En el mismo se determinó que debía atribuírseles a los árbitros la facultad de tanto de determinar el alcance del acuerdo arbitral como de su competencia y autoridad hacia el mismo. La Comisión de las Naciones Unidas para el Derecho Mercantil Internacional (CNUDMI en español, UNCITRAL en inglés, como comúnmente se conoce) adoptó oficialmente el principio "Kompetenz-Kompetenz", estableciendo al respecto en el artículo 21, numeral 1 de su Reglamento de arbitraje, lo siguiente: "El tribunal arbitral estará facultado para decidir acerca de las objeciones de que carece de competencia, incluso las objeciones respecto de la existencia o la validez de la cláusula compromisoria o del acuerdo de arbitraje separado". Posteriormente, en 1985, estableció en el artículo 16, numeral primero: "Facultad del tribunal arbitral para decidir acerca de su competencia... El tribunal arbitral estará facultado para decidir acerca de su propia competencia, incluso sobre las excepciones relativas a la existencia o a la validez del acuerdo de arbitraje. A ese efecto, una cláusula compromisoria que forme parte de un contrato se considerará como un acuerdo independiente de las demás estipulaciones del contrato. La decisión del tribunal arbitral de que el contrato es nulo no entrañará ipso jure la nulidad de la cláusula compromisoria”.

${ }^{18}$ Sobre las implicancias y connotaciones de este principio, véase, entre otros, GÓMEZ JENE (2000) p. 104; CARDASO (2004) 255-267; GISBERT (2004) pp. 135-139.
} 
de sede contractual, sus efectos se explican por medio de la ley, pues de lo contrario no sería factible que el árbitro pueda conocer del convenio que le sirve de antecedente a su competencia, si este es nulo.

Este asunto engarza, además, con la autonomía del convenio arbitral al comprender que el acuerdo arbitral siempre debe entenderse separado del contrato del que pueda formar parte, de forma tal que la nulidad de este último no pueda afectar la validez de la cláusula arbitral.

En resumen, a partir de este principio el árbitro no debiera interrumpir el procedimiento si se impugna su competencia en razón de inexistencia o nulidad ab initio del contrato que contiene el convenio o si se impugna la validez de la cláusula que le otorga competencia. En ambos casos, quien debe resolver es él, dado que no hay lugar de sospecha a priori sobre el hecho de que los árbitros no estén al nivel o con la debida mesura para arribar por ellos mismos a una decisión a la vez equitativa y protectora de los intereses de las partes ${ }^{19}$. Derivado de ello, esta regla y la de autonomía del convenio arbitral, se encuentran funcionalmente conectadas ya que la finalidad de ambas es la de impedir la posibilidad de fuga a la jurisdicción del arbitraje pactado.

Los tribunales estatales se encontrarán inhibidos para conocer de una materia que ha sido entregada a la justicia arbitral, y deberá remitir a las partes a esta última, a menos que compruebe que el convenio es nulo, ineficaz o de ejecución imposible (Art. 8 $\mathrm{LMU}^{20}$.

En esta línea se inscribe la sentencia pronunciada en la causa "Marlex Ltda. Con European Industrial Engineering", No 2026-2007, Corte Suprema, 28 de julio de 2008. En ella puede apreciarse un claro reconocimiento de este principio, según pasamos a revisar.

Se inició una demanda de cobro de pesos ante un tribunal ordinario de Antofagasta (Chile), frente a lo cual la parte contraria planteó un incidente de nulidad de todo lo obrado por incompetencia del tribunal, por haberse pactado una cláusula arbitral en el contrato respectivo. El contrato, que contenía una cláusula arbitral, se había celebrado entre una empresa chilena y una sociedad constituida de conformidad con las leyes de la República de Italia y con domicilio en la ciudad de Venecia.

La resolución judicial que resolvió el incidente de nulidad por falta de competencia, fue confirmada por la Corte de Apelaciones, siendo este último fallo objeto de una casación en el fondo ante la Corte Suprema.

El fallo objeto del recurso establece que se acordó por las partes una cláusula compromisoria, haciendo uso de la autonomía de la voluntad y libertad contractual y, tratándose de una materia en que el arbitraje no está prohibido por la ley, no puede sino determinarse que el tribunal estatal es incompetente para conocer del presente asunto, debiendo acogerse la nulidad solicitada, por no ser aplicable en la especie la norma del Art. 1462 del CC. Por su parte, ninguna ley chilena impide a las partes pactar en Chile o en el extranjero una cláusula de sumisión a favor de un tribunal extranjero. El ejemplo

${ }^{19}$ FERNÁNDEZ ROZAS et al. (2009) p. 649.

${ }^{20}$ VÁSQUEZ (2010) pp. 181-196. 
de objeto ilícito contenido en el Art. 1462 del CC no se refiere a estos últimos, que no tienen por qué ser reconocidos por las leyes chilenas, sino que a jurisdicciones privadas establecidas en Chile, distintas de los tribunales ordinarios o especiales a que alude el Art. 5 del Código Orgánico de Tribunales.

En el recurso de casación en el fondo se denuncian infringidos los artículos 80 de la Constitución Política de la República, $1^{\circ}$ y $5^{\circ}$ del Código Orgánico de Tribunales y 14 y 1462 del Código Civil. Argumenta la recurrente que la fundamentación contenida en la sentencia impugnada no se ajusta a Derecho, por cuanto el contrato que motiva el juicio no tenía ni remotamente la calidad de contrato internacional, dado que era una convención interna o nacional, que solo puede regirse por la ley chilena y respecto de la cual no es procedente someterse a la jurisdicción de los tribunales de Estados extranjeros.

En su sentencia, la Corte Suprema recurre a los principios generales del Derecho Internacional Privado para determinar que "el ordenamiento nacional reconoce explícitamente la posibilidad que los particulares estipulen someter las controversias que de la aplicación de un contrato internacional pudieran derivarse, al conocimiento de tribunales extranjeros, sean ellos ordinarios o arbitrales. Por ende, ningún objeto ilícito hay en la cláusula del contrato suscrito entre las partes, en virtud de la cual acuerdan entregar el conocimiento de los eventuales litigios que de este se pudieran suscitar, a un tribunal italiano y, por lo mismo, no comete error de derecho la sentencia que declara la incompetencia del tribunal ante el cual se interpuso la demanda para conocer del litigio promovido".

Como se puede observar, la Excelentísima Corte, una vez comprobada la validez de la cláusula arbitral, remite a las partes al arbitraje confirmando, de este modo, el principio en cuestión (Esta sentencia fue acordada con el voto en contra del Ministro Sr. Muñoz quien fue de parecer de acoger el recurso de casación).

\subsection{NeUtRALidAD Y RECONOCIMIENTO DE SENTENCIAS ARBitrales EXTRANJERAS}

La neutralidad implica que el foro no debe imponer su idiosincrasia a las partes en temas cuyo contenido depende del Derecho nacional, tales como la arbitrabilidad o el orden público. En tal sentido, el Estado sede debiera cuidar de dejar al margen sus propias nociones de orden público doméstico en favor de una noción de orden público internacional que tenga en cuenta la diversidad sociojurídica del mundo y los estándares generalmente aceptados por la comunidad internacional. Este último podría convertirse en un punto especialmente conflictivo, pues la LACI aplica criterios amplios sobre estas materias, por lo que se debe tener especial precaución en la configuración de las causales del recurso de nulidad, específicamente, con la falta de arbitrabilidad, la contrariedad al orden público ${ }^{21}$.

${ }^{21}$ Es importante destacar en esta línea, que el orden público del lugar del arbitraje cobra decisiva importancia para los árbitros comerciales internacionales, principalmente desde la óptica adjetiva. Véase GRIGERA (2002). 
Cabe recordar que el hecho que el Estado sede de un arbitraje no necesariamente será aquel en que se ejecute el laudo, de manera que no obstante contemplarse en los Arts. 34 y 36 de la LACI casi idénticas causales ${ }^{22}$, tanto para el recurso de nulidad como para denegar el reconocimiento de una sentencia arbitral extranjera, el juez estatal ha de emplear un criterio distinto ${ }^{23}$.

Lo anterior se debe a que el juez de impugnación debe tener como norte una resolución que transcienda sus fronteras ${ }^{24}$, pues declarada la nulidad del laudo arbitral, esta tendrá -en principio- efectos para todas las legislaciones en que se pretenda reconocer y que siguen este planteamiento, a diferencia de la decisión del juez del reconocimiento, que afecta solo al país en que se pretende reconocer y ejecutar la sentencia ${ }^{25}$. Esta apreciación es importante pues si estamos ante un laudo arbitral que no ha sido impugnado ante el juez en el Estado donde se ha pronunciado, la tutela jurisdiccional se desplaza necesariamente al juez del reconocimiento. En tal sentido, los motivos para denegar el reconocimiento o la ejecución de un laudo solo son válidos y eficaces en el Estado o Estados en los que la parte vencedora pretenda su reconocimiento y ejecución, en tanto que los motivos de nulidad tienen repercusiones más amplias, en tanto impide que los demás Estados puedan proceder a su ejecución ${ }^{26}$.

La mayor parte de los fallos dictados por los tribunales chilenos sobre esta materia, inciden en el reconocimiento de sentencias extranjeras. De la revisión de los mismos es posible concluir que la posición de Chile, como ejecutora de sentencias arbitrales internacionales, sigue los lineamientos formulados para el reconocimiento de toda sentencia extranjera, con lo que muestra un respeto por la institución y fallos arbitrales.

A. Caso: "Maw Mauro Stubrin v. Sociedad Inversiones Morice", Rol No 66002005, Corte Suprema, 11 de enero de 2007

Se solicita exequátur de la sentencia dictada por el tribunal arbitral pronunciada en Argentina bajo las reglas de la Comisión Interamericana de Arbitraje Comercial (CIAC), en un juicio en que los señores Max Mauro Stubrin, Walter Gerardo Stubrin,

\footnotetext{
${ }^{22}$ El Art. IX del Convenio Europeo sobre Arbitraje Comercial Internacional o Convenio de Ginebra (CG) ha suprimido las causales referidas a la arbitrabilidad y la contrariedad al orden público, por la posibilidad existente de que sean controladas por el juez del exequátur. Esto impide un doble control sobre las mismas materias que, en el arbitraje comercial internacional, encerraría un riesgo evidente: la duplicidad de ordenamientos nacionales proyectándose sobre las mismas categorías, en momentos diferentes y ante dos jurisdicciones distintas.

23 Sobre la posible desaparición del recurso de nulidad, PEREZnieTo y GRAHAM (2006) pp. 595-607. Los autores explican esta situación a partir de una reiterada corriente jurisprudencial que ejecuta los fallos en sus respectivos países, no obstante haber sido ellos anulados en el Estados sede. En otros casos, los países han sencillamente eliminado el recurso de sus legislaciones o han permitido su renuncia, básicamente por considerar que la sede responde solo a una ficción legal.

${ }^{24}$ Como explica ARTUCH (1997) pp. 153 y sgtes.: es necesario recordar que se trata del plano internacional, de manera que la interpretación y calificación de los conceptos, en buena lógica, va a responder al campo en que se proyecta.

${ }^{25}$ CUARTERo (1997) p. 26.

${ }^{26}$ Véase, Art. V.1, e) CNY y Art. 36.1 LMU.
} 
Darío Stubrin y Jacquelin Stubrin demandaron a la Sociedad Inversiones Morice SA por incumplimiento de su obligación de pago contenida en un contrato de compraventa de capital accionario suscrito entre las partes con fecha 26 de diciembre de 2000, y en que se resolvió condenar a Inversiones Morice.

El demandado invocó la violación del orden público, consagrada en el artículo V.2 de la Convención de Nueva York sobre Reconocimiento y Ejecución de las Sentencias Arbitrales Extranjeras, como una causal para denegar el reconocimiento a un laudo arbitral extranjero. En concreto, alegaba que esta Convención establece normas y exigencias específicas sobre reconocimiento y ejecución de sentencias arbitrales extranjeras, debiendo la parte que solicita dicho trámite presentar junto con la demanda o requerimiento: 1. El original debidamente autentificado de la sentencia o una copia de ese original que reúna las condiciones requeridas para su autenticidad. 2. El original del acuerdo por el que las partes se obligan a someter a arbitraje todas las diferencias o ciertas diferencias que hayan surgido o puedan surgir entre ellas respecto de una determinada relación jurídica, contractual o no contractual, concerniente a un asunto que pueda ser resuelto por arbitraje; o una copia de ese original que reúna las condiciones requeridas para su autenticidad.

La Corte, atendido el mérito y tenor de las certificaciones de la causa, emanadas del Secretario de la Excma. Cámara Nacional de Apelaciones en lo Comercial de la Capital Federal de la República Argentina y del Secretario del Tribunal Arbitral de la Comisión Interamericana de Arbitraje Comercial, respectivamente, desprende la eficacia de la solicitud. De ello desprende que la sentencia pronunciada por el señalado Tribunal Arbitral, perteneciente a la Comisión Interamericana de Arbitraje Comercial Internacional, se encuentra ejecutoriada, cumpliendo todos los requisitos del Art. 4o de la CNY, en concordancia con lo previsto en el Art. 242 del CPC, por lo que otorga el exequátur solicitado.

\section{B. Caso "Gold Nutrition Industria y comercio v. Laboratorios Garden House} SA", Rol No No 6615-2007, Corte Suprema, 15 de septiembre de 2008

Los representantes de Gold Nutrition Industria y Comercio solicitan se conceda el exequátur declarando que puede cumplirse en Chile la sentencia arbitral extranjera que se encuentra ejecutoriada desde el año 2007, pronunciada por el tribunal arbitral designado conforme a las normas de la Cámara de Mediación y Arbitraje de São Paulo y que condena a Garden House SA, que condenó al pago de una suma de dinero al demandado de dicha causa.

El fallo de la Corte Suprema rechazó una serie de argumentos expuestos por la parte demandada en los que se solicitaba el rechazo del exequátur. El Excelentísimo tribunal consideró que la solicitud debía ser resuelta a la luz de lo dispuesto en los artículos 242 y siguientes del Código de Procedimiento Civil y especialmente atento lo estatuido en la Ley 19.971, sobre Arbitraje Comercial Internacional, sin perjuicio de las normas que establecen tanto la Convención sobre el Reconocimiento y Ejecución de las sentencias Arbitrales Extranjeras de Naciones Unidas de 1958, y la Convención Interamericana sobre Arbitraje Comercial Internacional de 1975. 
Precisa que este procedimiento no constituye una instancia, por lo que no es dable promover ni resolver dentro de él materias propias a los hechos y el derecho relativas a la causa en que se dictó la sentencia extranjera, ni tampoco pueden ser resueltas alegaciones que puedan constituir excepciones que deban ser opuestas en la ejecución correspondiente y ante el Tribunal que conoce de ella. En definitiva corresponde a esta Corte, a la luz de los antecedentes allegados a estos autos, examinar el cumplimiento de los requisitos previstos en el artículo 36 de la Ley 19.971, y 242 y siguientes del Código de Procedimiento Civil, puesto que el demandado alega que no se reúnen las condiciones copulativas que la ley establece.

En relación con la alegación del oponente en orden a que el nombramiento de los árbitros emanó de un ente privado, sostiene que aquella carece de todo fundamento, en razón de que tuvo como origen una orden de un Tribunal Civil, 19 Juzgado Civil del Foro central de la circunscripción de São Paulo, integrado por 3 miembros, dos de ellos designados por las partes y el tercero nombrado por los dos anteriores, lo que se encuentra en perfecta concordancia con lo establecido en el artículo 11 No 3 de la Ley 19.971, fundamento suficiente para desestimar la alegación del demandado. Enseguida y en relación a la falta de validez de la cláusula compromisoria por su ambigüedad, falta de completitud e imprecisión, cabe señalar que dichos argumentos fueron desestimados por el citado Juzgado, sin que exista una sentencia ejecutoriada que declare la nulidad de la misma, argumento bastante para desestimar dicha alegación.

En relación a la alegación que se han infringido las leyes de la república, específicamente el artículo 9 de la Ley 18.010, en lo relativo al pago de intereses, por cuanto a su juicio ha existido anatocismo, lo que se encuentra prohibido por la legislación nacional, la Corte expresa que dicha argumentación es de fondo, y escapa por ello el control del exequátur, por lo que no corresponde a este Tribunal pronunciarse sobre la materia sino a aquel que conozca de la ejecución del fallo.

Que en cuanto a que el laudo cuyo cumplimiento se solicita no se encontraría ejecutoriado, resulta útil consignar que esta alegación resulta contraria a lo que se certificó en los antecedentes que rolan en autos. De manera que, encontrándose ejecutoriada la sentencia y habiéndose dado cumplimiento a cada uno de los requisitos de la Ley 19.971 en relación al artículo 242 y siguientes del Código de Procedimiento Civil, se aceptará la eficacia del fallo cuya autorización para su cumplimiento se solicita, accediendo a la petición de exequátur.

C. Caso: "Comverse Inc. cl American Telecommunication, Inc. Chile SA", Rol $N^{o} N^{o}$ 3225-2008, Corte Suprema, 8 de septiembre de 2009

La solicitud de exequátur recayó en una sentencia arbitral dictada en un procedimiento con sede en EE.UU. En su análisis, la Corte Suprema partió de la premisa que la función del exequátur consiste en "verificar el cumplimiento de ciertos requisitos mínimos y no se encuentra destinado, de manera alguna a analizar la justicia o injusticia intrínseca de la sentencia de modo que de manera alguna constituye una instancia de revisión de lo allí resuelto" (Considerando séptimo). 
Teniendo en consideración que la solicitud de concesión de exequátur está destinada solamente a habilitar la iniciación de un juicio ejecutivo dentro del cual podrá debatirse lo alegado, y que la excepción deducida corresponde claramente a aquella contemplada en el $\mathrm{N}^{\circ} 2$ del artículo 464 del Código de Procedimiento Civil, resulta improcedente promoverla y resolverla en esta etapa. Adicionalmente, el máximo Tribunal expresa que no puede dejar de hacerse presente que los fundamentos que sirven de sustento a esta excepción de falta de legitimación en el demandante por no haber acreditado la existencia de la empresa ni que quien demanda sea su representante, pues de ser efectivos, correspondía fueran reclamados en el juicio arbitral, cuestión que no consta haya sucedido y en cuyo laudo arbitral se consignó particularmente que la sociedad actora es una empresa legalmente constituida y vigente, y que quien acciona como su representante, lo es.

Tratándose de un incumplimiento de contrato mercantil internacional en el que las partes se sometieron a un tribunal arbitral y a un derecho extranjero, resulta que en la presente gestión únicamente pueden revisarse las alegaciones que se sustenten en aquellas exigencias y excepciones señaladas en los artículos IV y V de la Convención de Nueva York, respectivamente, norma esta última que se encuentra reiterada por el artículo 36 de la Ley 19.971 -las que, por cierto, también pueden ser opuestas durante la ejecución por la parte contra la cual se invoca-, sin embargo, los argumentos sobre las cuales la demandada construye la excepción referida no configuran ninguna de aquellas de las que trata el precepto mencionado, motivo por el cual no se justifica su análisis, el cual deberán las partes reservar para la oportunidad pertinente, por lo que la excepción entablada por la demandada será rechazada en este procedimiento de exequátur.

La alegación de la demandada en el contrato mercantil internacional, consistente en haberse incurrido en la causal que permite denegar el reconocimiento y ejecución de la sentencia prevista tanto en el numeral 1 letra b) del artículo 5 de la Convención de Nueva York como en el número 1 letra a) ii) del artículo 36 de la Ley 19.971 sobre arbitraje comercial internacional, esto es, por haberse vulnerado su derecho de defensa durante la substanciación del juicio que dio lugar a la sentencia cuya ejecución se pretende en Chile, procede consignar que de los propios argumentos vertidos por dicha parte se desprende palmariamente que aquella no solo no se vio impedida de ejercer su derecho a la defensa sino que, según ella misma lo reconoce, compareció al juicio arbitral realizando alegaciones y defensas, opuso la excepción de contrato no cumplido; presentó demanda reconvencional, que fue acogida parcialmente y, en su oportunidad, presentó prueba documental y testimonial, lo que alcanza para concluir que la demandada no se vio privada de la posibilidad de hacer valer sus medios de defensa, derecho salvaguardado constitucionalmente, constatándose en cambio que lo que realmente dicha parte ataca es el fondo de la decisión adoptada por los jueces extranjeros, así como la ponderación que hicieron de las pruebas allegadas a dicho procedimiento, cuestiones estas que en los términos que ya se han expuesto, no pueden ser revisadas dentro del procedimiento de exequátur.

Es irrevisable en el procedimiento de exequátur de la sentencia arbitral recaída en el marco de un incumplimiento de contrato mercantil internacional, la alegación de 
supuesta falta de imparcialidad del tribunal arbitral, reclamada por la oponente, desde que su fundamento se lo hace consistir en simples conjeturas, las cuales, a su vez, se construyen sobre la base de una decisión que considera injusta, desde que, no se indica ningún medio probatorio que requerido, ofrecido o solicitado no se aceptara o no se pudiera rendir ante el tribunal, por lo que la oposición formulada por este motivo debe ser necesariamente desestimada.

Considerándose que nos encontramos frente a lo que la doctrina denomina contratos internacionales, respecto de los cuales la dogmática está acorde en darle validez a las cláusulas en las que se acuerde dar jurisdicción a tribunales extranjeros, y nuestro legislador también reconoce tal posibilidad bajo ciertas condiciones en relación a la materia, las personas y carácter de los tribunales llamados a resolver, por lo que la alegación resulta inatendible $y$, en definitiva, la oposición debe ser rechazada en todos sus extremos.

Junto con invocar la Ley 19.971 sobre Arbitraje Comercial Internacional, la Corte recurrió a la Convención de Nueva York sobre el reconocimiento y ejecución de las sentencias arbitrales extranjeras, la Excma. Corte concluye que corresponde acoger el exequátur solicitado y, en consecuencia, autorizó que se cumpla en Chile la sentencia arbitral dictada en otro país.

\section{Caso: "Kreditanstalt Für Wiederaufbau v. Inversiones Errázuriz", Rol $N^{o}$ 5228-2008, Corte Suprema, 15 de diciembre de 2009}

La solicitud de exequátur recayó en una sentencia dictada en un procedimiento arbitral desarrollado en París, Francia. El citado tribunal se constituyó de conformidad con el reglamento de arbitraje de la Cámara de Comercio Internacional (Rol No 14158/ $\mathrm{RCH} / \mathrm{JHN}$ ), con sujeción a las normas de procedimiento aplicables de acuerdo al Reglamento de Arbitraje de la CCI y condenó, en definitiva, a Inversiones Errázuriz Limitada a pagar una determinada suma de dinero a la demandante.

La parte demandada se opuso al reconocimiento de la sentencia arbitral invocando, en particular que: 1. La parte solicitante no dio cumplimiento al Art. IV.2 de la Convención de Nueva York, sobre el Reconocimiento y Ejecución de las Sentencias arbitrales Extranjeras. 2. La parte de Inverraz no fue debidamente notificada de la designación del árbitro o del procedimiento de arbitraje y no pudo hacer valer sus medios de defensa. 3. La sentencia se refiere a una diferencia no prevista en el compromiso y no comprendida en las disposiciones de la cláusula compromisoria y contiene decisiones que exceden de los términos del compromiso o de la cláusula compromisoria. 4. El procedimiento arbitral no se ajustó al acuerdo celebrado entre las partes. 5. La sentencia no es aún obligatoria para las partes y ha sido suspendida en el Estado en que, conforme a cuya ley, ha sido dictada esa sentencia. 6. En Chile el objeto de la diferencia no es susceptible de solución por vía de arbitraje. Y 7. El reconocimiento y la ejecución de la sentencia arbitral son contrarios al orden público.

Inverraz arguye que el objeto de la diferencia no es susceptible de solución por vía de arbitraje, puesto que la sentencia arbitral se funda en una cláusula compromisoria suscrita y terminada por el contrato de transacción acordado entre su parte y KFW, 
entidad bancaria de derecho público. Esta última es una corporación de derecho público, sin fines de lucro. De este modo, y de acuerdo a lo prescrito en los Arts. 230 y 357 del Código Orgánico de Tribunales chileno, no podría ser sometida a arbitraje.

Por su parte, agrega que el tribunal arbitral constituido a estos efectos, viola el orden público contenido en el Art. 222 del Código Orgánico de Tribunales de Chile, que dispone que los árbitros son jueces nombrados por las partes o por la autoridad judicial en subsidio. La Corte Internacional de la Cámara de Comercio Internacional no es un tribunal de justicia de la República Francesa sino que únicamente un órgano administrativo privado. El tribunal arbitral sería, para su defensa, una simple comisión especial que conforme a lo dispuesto en el Art. 19 No 3 inc. $4^{\circ}$ de la Constitución Política de la República, se encuentra prohibida.

Asimismo, sostiene que la sentencia no sería aún obligatoria para las partes, pues se habría suspendido en el Estado en que, conforme a cuya ley, ha sido dictada esa sentencia (Art. 36 a, No 1, apartado v, Ley 19.971), esto es, Francia, por aplicación del Art. 1505 del CPC francés, como consecuencia de la acción de nulidad deducida por la parte demandada. Acompaña a estos efectos un informe en derecho elaborado por el profesor de derecho arbitral e internacional francés, Charles Jarrosson.

Frente a estos argumentos, la Corte Suprema señala que el objeto de la controversia que resolvió el laudo arbitral en cuestión es susceptible de arbitraje de acuerdo a las leyes chilenas, por cuanto no se encuentra dentro de los casos de arbitraje prohibido. El laudo cuyo exequátur se solicita no contraviene el orden público chileno, habiéndose notificado el inicio del arbitraje a Inverraz y dado razonable oportunidad de defensa a la demandada, quien se apersonó en el juicio e hizo valer sus medios de defensa. El referido laudo acoge una acción civil derivada del incumplimiento de dos contratos de préstamo, condenando a la demandada al pago de determinadas sumas de dineros adeudadas más las costas. La acción deducida es una simple aplicación de uno de los principios más fundamentales de nuestro ordenamiento jurídico, cual es que lo pactado obliga a las partes o Pacta Sunt Servanda.

Asimismo, recogiendo en su sentencia los planteamientos presentados en un informe de la Fiscal Judicial, concluyó que no procede denegar el reconocimiento de la sentencia arbitral extranjera. La Corte explicó que la existencia de un proceso de anulación pendiente no era suficiente para denegar el exequátur, para ello es necesario que se acredite la correspondiente anulación o suspensión del fallo. A mayor abundamiento, el máximo tribunal chileno subrayó que la ley aplicable al reconocimiento de la sentencia extranjera es la ley nacional, y por ende no tiene relevancia que, según el derecho francés, la interposición del recurso de nulidad pueda tener para el laudo arbitral efectos suspensivos.

La Corte Suprema consigna que se está en presencia de un contrato mercantil internacional y que es aplicable la Ley 19.971 sobre arbitraje comercial internacional.

Concluye, luego de hacerse cargo de todos los argumentos de la parte opositora del exequátur, que el laudo arbitral en referencia es eficaz, por lo que se acoge el exequátur solicitado, autorizando a que se cumpla en Chile la sentencia arbitral dictada el 1 de octubre de 2007, en París. 


\section{E. Caso: "Stemcor UK Limited and Compañia Comercial Metalúrgica} Limitada”, Rol No 1724-2010, Corte Suprema, 21 de junio de 2010

Se solicita exequátur respecto de una sentencia arbitral dictada en un procedimiento administrado por la Corte de Arbitraje Internacional de Londres. La parte demandada en el arbitraje, si bien había participado en la designación del árbitro de común acuerdo, con posterioridad no intervino en el proceso arbitral, dictándose sentencia en su contra.

La sentencia de la CS dedica una especial atención a la determinación de la normativa aplicable al reconocimiento de las sentencias arbitrales extranjeras, cuyos pilares se encuentran en los artículos 242 a 251 del Código de Procedimiento Civil. Dentro de ese sistema se aplica la reciprocidad legal o interpretativa y, en ausencia de esos antecedentes, pasa a regir el criterio de la regularidad internacional (considerando No 3). Agrega que en el caso en estudio se está en presencia de un contrato mercantil internacional, de esta forma, ante los claros términos de la Ley 19.971, la regularidad de la sentencia cuya autorización para el cumplimiento en Chile se requiere, debe ser estudiada al tenor de la normativa, sin dejar de tener presente la Convención de Nueva York, puesto que fue este marco regulatorio el atendido y sobre la base de cuya aplicación se desarrolló el arbitraje. Al tenor de lo referido en los considerandos previos, corresponde se precise el contenido de los artículos 35 y 36 de la Ley 19.971, preceptos que son similares a aquellos recogidos en la Convención de Nueva York.

Si bien la parte requirente en su solicitud ha sostenido que la sentencia pronunciada por el tribunal arbitral reúne todas las condiciones exigidas por el marco legal para su otorgamiento, frente a dicha petición y a tales asertos, la parte contra la cual se invoca el fallo, cuyo reconocimiento y ejecución se pretende, no se ha opuesto ni ha formulado observación alguna, y mucho menos ha aportado antecedentes tendientes a demostrar la concurrencia de alguna de las situaciones transcritas en el motivo que antecede (Considerando octavo).

La Corte señala que, no obstante ser lo anterior suficiente para conceder el exequátur pedido por Stemcor UK Limited, de todos modos, y en concordancia con lo expresado con la Sra. Fiscal Judicial, resulta procedente consignar que del mérito de los antecedentes aportados a esta gestión, se constata que los dos contratos de compraventa suscritos por las partes, incluyen la cláusula de arbitraje, por la que se pacta que cualquier diferencia relacionada con el contrato "será sometida a arbitraje en conformidad con las normas de LCIA, en idioma inglés, en Londres, ante un único árbitro, que será designado entre el comprador y el vendedor. De no llegarse a acuerdo respecto del árbitro, este será designado por LCIA". Asimismo, se constata que durante la substanciación del juicio arbitral la demandada no se vio impedida de ejercer su derecho a la defensa sino que simplemente decidió, de forma voluntaria, mantenerse rebelde en aquel procedimiento, no obstante haber sido debidamente emplazada, actitud esta que no puede, de manera alguna, identificarse con indefensión.

El máximo tribunal concluye que todas estas argumentaciones llevan a aceptar la eficacia del fallo cuya autorización se solicita, lo que se dispondrá, accediendo al exequátur solicitado. 
F. Caso: "Western Technologi Services Internacional Inc. con sociedad chilena Cauchos Industriales S.A.(Cainsa)", Rol No No 5468-2009, Corte Suprema, 11 de mayo de 2010

Se solicita exequátur respecto de una resolución arbitral dictada en Dallas, Texas, EE.UU., concediendo una medida precautoria que afecta a Cauchos Industriales S.A. o Cainsa, referida a las siguientes prohibiciones: a) Contratar, tratar o intentar contratar a una persona que sea trabajador o contratista independiente de Westech o de alguna de sus filiales, o incentivar en alguna forma a esa persona para poner término a su relación con Westech o alguna de sus filiales o incentivar en alguna forma a esa persona para trabajar en, para o con alguna otra persona o entidad, o recurrir a esa persona para alguno de dichos propósitos; b) Interferir, o intentar interferir en la relación contractual o de otra índole existente entre Westech y alguno de sus clientes, proveedores o consultores con respecto a los negocios restringidos (según se definen en el párrafo o más adelante); c) Obtener o tratar de obtener pedidos de cualquier persona o entidad que sea o haya sido cliente de Westech en cualquier momento durante la vigencia del contrato de uso, en relación con los negocios restringidos (según se definen en párrafo 8 más adelante); d) Dedicarse a cualquier actividad competitiva (según se define en el párrafo 7 más adelante) o a negocios restringidos (según se define en el párrafo 8 más adelante) en cualquier parte del territorio (según se define en el párrafo 3 precedente); e) Usar o divulgar información confidencial, secretos comerciales o tecnología de Westech (según la definición de los términos información confidencial, secretos comerciales y tecnología en el artículo 1 del Contrato de Uso de Tecnología), lo que incluye, entre otros, información de los clientes de Westech, datos de ventas, información técnica, dibujos y especificaciones de ingeniería, información y materiales de investigación y desarrollo, datos de márgenes de utilidades, datos de costos de productos vendidos. Se agrega que esta orden precautoria preliminar se prorrogará y no vencerá hasta que este tribunal dicte una nueva resolución o hasta que las partes convengan algo distinto.

$\mathrm{Al}$ analizar los antecedentes, la CS establece que se trata de una orden precautoria preliminar en contra de la demandada y que al acogerla el tribunal arbitral manifestó "Que esta orden precautoria preliminar se prorrogará y no vencerá hasta que este tribunal dicte una nueva resolución o hasta que las partes convengan algo distinto”.

La CS enfatizó que la normativa vigente en Chile se aplica al reconocimiento de sentencias dictadas por tribunales extranjeros, no es aplicable al cumplimiento de medidas cautelares dictadas por dichos tribunales. A juicio de la CS, la sentencia interlocutoria en comento no establece derechos permanentes para las partes, desde que el propio tribunal que la dictó, le dio el carácter de preliminar y porque en definitiva, las medidas precautorias son esencialmente provisionales (Considerando $5^{\circ}$ ).

De acoger la petición del exequátur, la concreción y mantenimiento en el tiempo de dichas medidas llevaría a decidir, desde ya, acerca de las principales peticiones planteadas en la demanda (Considerando 6). Por lo anterior, se rechaza la solicitud de exequátur. 


\section{ALGUNAS REFLEXIONES PARA FINALIZAR}

1. A partir del análisis de las sentencias judiciales pronunciadas por los máximos tribunales de justicia chilenos, es posible advertir la real acogida que ha tenido la LACI en Chile, la que se constata en términos positivos a partir de la revisión de los principios más relevantes de la institución.

2. El principio de intervención mínima ha sido recogido por los máximos tribunales de justicia chilenos, al rechazar y/o declarar inadmisibles diversos recursos interpuestos a propósito de juicios arbitrales comerciales internacionales, que no sean expresamente previstos por la Ley de arbitraje comercial internacional, LACI.

Por este camino se ha declarado que la LACI es una norma de Derecho procesal que rige in actum, de manera que no es relevante para lograr su aplicación, que el contrato que motiva el arbitraje sea anterior a la misma.

3. El único recurso admitido por la LACI es el de nulidad que, como sabemos, no genera una segunda instancia, sino que solo permite la revisión de ciertas causales tasadas (Art. 34). A propósito de esta acción, los tribunales estatales han comprendido que no se encuentran facultados para revisar el fondo del juicio sometido a la justicia arbitral, evitando toda intervención que exceda la revisión de las causales en comento.

4. Asimismo, cuando han tenido que hacer frente a la alegación de un recurso de nulidad basado en la incompetencia de sus tribunales, por existir un convenio arbitral válido, los tribunales estatales han respetado lo dispuesto en el Art. $8^{\circ}$ de la LACI, declarando la nulidad del procedimiento, remitiendo con ello a las partes al arbitraje. Se ha reconocido con ello, igualmente, los principios generales del Derecho Internacional Privado, en relación a la validez de los contratos internacionales.

5. En relación a la ejecución de sentencias arbitrales extranjeras, se ha señalado que esta se rige por las reglas generales de toda sentencia extranjera. En dicho procedimiento, la Corte Suprema ha manifestado que son aplicables, además de la Convención de Nueva York y de Panamá, las normas de la LACI.

6. En reiteradas ocasiones se ha expresado que en la revisión de las sentencias arbitrales extranjeras, no les está permitido a los tribunales entrar a conocer el fondo del litigio, solo están facultados para revisar las causales contempladas por el Art. 36 de la LACI, en consonancia con lo prescrito en la CNY.

7. Asimismo, se expresa que solo las sentencias definitivas e interlocutorias que establezcan derechos permanentes para las partes, pueden ser objeto de este procedimiento. Las restantes, incluidas las resoluciones que fijen medidas precautorias, no podrían ser cumplidas por esta vía, de manera que habría que concluir que la solicitud de tales medidas debiera presentarse directamente ante los tribunales chilenos, según lo que se desprende del Art. 9 de la Ley 19.971. De manera que los tribunales ordinarios de Chile tienen competencia para otorgar medidas cautelares, aunque exista un tribunal arbitral constituido y la sede del arbitraje se encuentre en país extranjero.

8. El panorama que se constata a partir de la revisión de estos fallos precedentes nos permite asegurar no solo una total incorporación de la LACI en nuestra cultura 
jurídica, sino, más aún, que Chile está en buen pie para convertirse en una importante sede arbitral en la región.

\section{BIBLIOGRAFÍA CITADA}

Anuario de la Comisión de las Naciones Unidas para el Derecho Mercantil, vol. XVI (1985).

ARTUCH IRIBERRI, E. (1997): El convenio arbitral en el arbitraje comercial internacional (Madrid, Editorial Eurolex).

BARONA VILAR, Silvia (coord.) (2005): Comentarios a la ley de arbitraje (ley 60/2003, de 23 de diciembre) (Barcelona, Thomson Civitas).

Cardaso Palau, J (2004): "Potestad de los árbitros para decidir sobre su propia competencia", en Comentarios a la nueva ley de arbitraje 60/2003, de 23 de diciembre (coord. Julio González Soria) (Navarra, Ed. Thomson - Aranzadi).

BERnARDo SAN José, Bernardo (2002): Arbitraje y jurisdicción. Incompatibilidad y vías de exclusión (Granada, Editorial Comares).

Chatterjeek (2003): "The Reality of the Party Autonomy Rule in International Arbitration", Journal of International Arbitration, vol. 20 No 6, dic., pp. 539-560.

Chillón Medina, J.F. y Merino Marchant, J.M (1991): Tratado de arbitraje privado interno e internacional (Madrid Ed. Civitas).

CREmades, Bernardo María (1999): “Arbitraje y desarrollo económico mundial”, Rev. Iberoamericana de arbitraje, disponible en: <<http//:www.servilex.com.pe/arbitraje/ congreso.panama/b-11.html >> [fecha de consulta: 25 de marzo de 2011].

CuARTero Rubio, María Victoria (1997): El recurso de anulación contra el laudo arbitral en el arbitraje comercial internacional (Madrid, Eurolex).

GÓMEZ JenE, Miguel (2000): El arbitraje internacional en la Unión Europea: la eficacia del laudo arbitral (Madrid, Ed. Colex).

GONZÁleZ-Montes SÁNCHEZ, José Luis (2008): El control judicial del arbitraje (Madrid, Editorial La Ley).

Hinojosa Segovia, Rafael (2006): Comentario a la ley de arbitraje (coord. A. De Martín Muñoz y S. Hierro Anibarro) (Madrid).

FERNÁNDEZ RozAS, José Carlos (2005): "El arbitraje comercial internacional entre la autonomía la anacionalidad y la deslocalización”, REDI, vol. LVII, pp. 605-637.

FERNÁNDEZ ROZAS, José Carlos (2005): "Arbitraje y jurisdicción: una interacción necesaria para la realización de la justicia”, Rev. Derecho Privado y Constitución, No 19, año 13 , pp. 55-91.

FERnÁNDEZ RoZAS, José Carlos, et al. (2007): Derecho de los negocios internacionales (Madrid, Editorial Iustel).

Fernández Ballesteros López, M.A. (2004): Comentarios a la nueva ley de arbitraje 60/2003, de 23 de diciembre (coord. J. González Soria) (Navarra) pp. 412-413.

Figueroa VAldés, Juan (2007): “Tópicos de la Ley No 19.971, sobre arbitraje comercial internacional", Estudios de arbitraje, Libro homenaje al Profesor Patricio Aylwin Azócar (Ed. Jurídica de Chile, Santiago) pp. 391-404. 
Gisbert Pomata, M. (2004): Comentarios a la ley de arbitraje. Ley 60/2003, de 23 de diciembre (coord. R. Hinojosa Segovia) (2 Grupo de Difusión, Madrid).

GonZÁlez CAmpos, Julio (1975): "Sobre el Convenio de arbitraje en el Derecho Internacional privado español", en Anuario de Derecho Internacional II, Facultad de Derecho de la Universidad de Navarra, pp. 3-42.

GOSWAMI, L. (2001): "Interim Reliefs: The role of the Courts", International Arbitration and National Courts: The never ending store, ICCA International Arbitration Conference, The Haghe.

Grigera NAON, H. (2002): "Los árbitros internacionales, ¿deben o pueden aplicar las leyes de policía?", Avances del Derecho Internacional Privado en América Latina, Liber Amicorum Jürgen Samtleben. Coordinadores: Jan Kleinheisterkamp y Gonzalo A. Lorenzo Idiarte (Montevideo, Editorial Fundación de Cultura Universitaria) disponible en: <<http://www.ccb.org.co/cac/docs/art_hgrigera.pdf >> [fecha de consulta: 25 de marzo de 2011].

LorCa NAVARrete, Antonio (2004): Comentarios a la nueva ley de arbitraje 60/2003 de 23 de Diciembre (San Sebastián, Instituto Vasco de Derecho Procesal).

M.I.M. Aboul-Enein (2001): "The contract: what causes Courts to disregard Agreements to arbitrate, and How can Duch agreements be improve to avoid that fate according to new Arab Laws of Arbitration", International Arbitration and National Courts: The never ending Story, ICCA International Arbitration Conference, The Haghe.

Pereznieto Castro, L. y Gram, J. A. (2006): “¿La muerte programada del Estado sede del arbitraje?”, en Estudios de arbitraje, Revista. Latinoamericana de Mediación y Arbitraje, vol. VI, No 2, pp. 595-607.

PeTSCHE, Markus A. (2005): The growing autonomy of international commercial arbitration (München, Alemania, European Law publishers).

SANDOVAL LÓPEZ, Ricardo (2007): "La normativa de UNCITRAL sobre arbitraje comercial internacional como instrumento de unificación”, en Estudios de arbitraje, Libro homenaje al Profesor Patricio Aylwin Azócar (Ed. Jurídica de Chile, Santiago) pp. 485-517.

SATELER, Ricardo (2007): "Historia de la Ley No 19.971 sobre arbitraje comercial internacional", en Estudios de arbitraje, Libro homenaje al profesor Patricio Aylwin Azócar (Santiago de Chile, Ed. Jurídica).

Senes Motilla, C (2007): La intervención judicial en el arbitraje (Madrid, Editorial Civitas).

VÁsquez Palma, María Fernanda (2009): Arbitraje en Chile, Análisis crítico de su normativa y jurisprudencia (Santiago de Chile, Editorial LegalPublishing).

VÁsqueZ Palma, María Fernanda (2010): “Comprensión del principio CompetenciaCompetencia y configuración de la nulidad o ineficacia del acuerdo arbitral”, Revista Chilena de Derecho Privado, No 15, pp. 181-196.

Verdera y TUells, Evilio (1994): "Algunas consideraciones en torno al arbitraje comercial", RCEA, pp. 137-177. 


\section{LEYES CITADAS}

Convención de Nueva York (CNY), sobre el Reconocimiento y la Ejecución de las Sentencias Arbitrales Extranjeras, de 10 de junio de 1958. Diario Oficial, 31 julio de 1975.

Convenio Europeo sobre arbitraje internacional de 1961 o Convención de Ginebra (CG).

Ley de arbitraje comercial internacional (LACI), No 19.971. Diario Oficial, 29 de septiembre de 2004.

Ley Modelo Uncitral sobre arbitraje comercial internacional (LMU), de 1985.

\section{JURISPRUDENCIA CITADA}

D’Arcy Masius Benton \& Bowles Inc. Chile Ltda. V. Carlos Eugenio Jorquiera (2006): Corte de Apelaciones, Rol No 88-2006, 3 de mayo de 2006.

D’Arcy Masius Benton \& Bowles Inc. Chile Ltda. Otero Lathrop Miguel (2006): Corte de Apelaciones, Rol No 865-2006, 25 de mayo de 2006.

Maw Mauro Stubrin v. Sociedad Inversiones Morice (2007): Corte Suprema, Rol No 6600-2005, 11 de enero de 2007.

Marlex Ltda. Con European Industrial Engineering (2008): Corte Suprema, Rol No 20262007, 28 de julio de 2008.

Gold Nutrition Industria y comercio v. Laboratorios Garden House SA. (2008): Corte Suprema, Rol No 6615-2007, 15 de septiembre de 2008.

Comverse Inc. cl American Telecommunication, Inc. Chile SA. (2009): Corte Suprema, Rol No 3225-2008, 8 de septiembre de 2009.

Kreditanstalt Für Wiederaufbau v. Inversiones Errázuriz (2009): Corte Suprema, Rol No 5228-2008, 15 de Diciembre de 2009.

Western Technologi Services International Inc. con sociedad chilena Cauchos Industriales S.A. (Cainsa) (2010): Corte Suprema, Rol No 5468-2009, 11 de mayo de 2010.

Stemcor UK Limited and Compañia Comercial Metalúrgica Limitada (2010): Corte Suprema, Rol No 1724-2010, 21 de junio de 2010.

Agricservices Chile Ltdalárbitro don Alejandro Romero Seguel (2010): Corte de Apelaciones de Santiago, Rol No 2363-2010, 23 de julio de 2010. 